\title{
Proteomic approaches to study epigallocatechin gallate-provoked apoptosis of TSGH-8301 human urinary bladder carcinoma cells: Roles of AKT and heat shock protein 27-modulated intrinsic apoptotic pathways
}

\author{
NIAN-GU CHEN ${ }^{1}$, CHI-CHENG LU ${ }^{2}$, YU-HSIN LIN ${ }^{3}$, WU-CHUNG SHEN ${ }^{4,7}$, CHENG-HUNG LAI $^{1}$, \\ YUNG-JEN HO ${ }^{5,7}$, JING-GUNG CHUNG ${ }^{3}$, TSAI-HSIU LIN ${ }^{8}$, YUNG-CHANG LIN ${ }^{1}$ and JAI-SING YANG ${ }^{6,9}$ \\ Departments of ${ }^{1}$ Veterinary Medicine, and ${ }^{2}$ Life Sciences, National Chung Hsing University, Taichung 402; \\ Departments of ${ }^{3}$ Biological Science and Technology, ${ }^{4}$ Radiology, ${ }^{5}$ Biomedical Imaging and Radiological Science, \\ ${ }^{6}$ Pharmacology, China Medical University, Taichung 404; Departments of ${ }^{7}$ Radiology and ${ }^{8}$ Laboratory Medicine, \\ China Medical University Hospital, Taichung 404; ${ }^{9}$ Department of Cosmetic Science, \\ Providence University, Taichung 433, Taiwan, R.O.C.
}

Received May 11, 2011; Accepted June 14, 2011

DOI: $10.3892 / o r .2011 .1377$

\begin{abstract}
Epigallocatechin-3-gallate (EGCG), a polyphenol constituent present in green tea, has been shown to inhibit the growth of cancer cells in vitro and in vivo. However, studies regarding human bladder carcinoma cells are limited and not well investigated. Hence, our study focused on the evaluation of EGCG-triggered apoptosis in TSGH-8301 human urinary bladder carcinoma cells in vivo and in vitro as well as its related molecular mechanisms. In an in vivo study, EGCG inhibited xenograft tumor size of TSGH-8301 cells in a nude mouse model. Based on an in vitro study, EGCG resulted in morphological changes and increased growth inhibition in a dose- and time-dependent manner in TSGH-8301 cells. Furthermore, sub-G1 populations were shown and caspase-9 and -3 activities were stimulated in EGCG-treated TSGH8301 cells. Moreover, a caspase-9 inhibitor (Z-LEHD-FMK) and a caspase-3 inhibitor (Z-DEVD-FMK) were able to reduce EGCG-stimulated caspase-9 and -3 activities, respectively. Loss of mitochondrial membrane potential $(\Delta \Psi \mathrm{m})$ resulted in an increase of protein levels of cytochrome $c$, Apaf-1, caspase- 9 and -3 in TSGH-8301 cells following exposure to EGCG. Proteomic analysis revealed that EGCG affected the
\end{abstract}

Correspondence to: Dr Jai-Sing Yang, Department of Pharmacology, China Medical University, No. 91, Hsueh-Shih Road, Taichung 40402, Taiwan, R.O.C.

E-mail: jaising@mail.cmu.edu.tw

Dr Yung-Chang Lin, Department of Veterinary Medicine, National Chung Hsing University, 250, Kuo Kuang Road, Taichung 40227, Taiwan, R.O.C

E-mail: ylin@nchu.edu.tw

Key words: proteomics, epigallocatechin-3-gallate, apoptosis, human bladder cancer TSGH-8301 cells, HSP27, AKT, intrinsic apoptotic signaling expression levels of various proteins, including HSP27, porin, tropomyosin 3 isoform 2, prohibitin and keratin 5, 14, 17 in TSGH-8301 cells. EGCG also suppressed AKT kinase activity and protein levels and also altered the expression levels of Bcl-2 family-related proteins such as Bcl-2, Bax, BAD and p-BAD. Based on the above findings, this study suggests that EGCGprovoked apoptotic death in TSGH-8301 cells is mediated through targeting AKT and HSP27 and modulating p-BAD, leading to activation of the intrinsic apoptotic pathway.

\section{Introduction}

Bladder cancer is one of the most common types of malignancies in human beings (1). Approximately 3.3 of 100 thousand people die from bladder cancer, and it is the 14th most common malignancy in Taiwan based on the report from the Department of Health, R.O.C. (Taiwan) in 2009 (2). In pathological analysis, $>90 \%$ of bladder cancers are transitional cell carcinomas (TCC) (3). For the clinical therapy of bladder cancer patients, surgery, radiotherapy and chemotherapy may be used (4-6). However, these current therapies modalities are insufficient because the median survival time is about one year and it is unsatisfactory since distant metastasis may occur (7). Therefore, discovering a new more effective anti-bladder cancer agent is necessary.

Polyphenols are a group of chemical substances in human diets (8). The major sources of dietary polyphenol are fruits, vegetables and green tea $(9,10)$. Many studies demonstrate that green tea can prevent chronic diseases and cancer in human bodies $(11,12)$. The most important polyphenols in green tea include epicatechin (EC), epigallocatechin (EGC), epicatechin gallate (ECG), and epigallocatechin gallate (EGCG) (13-15). EGCG has been reported to have biological functions (16-19) including anti-cancer activity (20). In vitro and in vivo studies have indicated that EGCG has chemopreventive and chemotherapeutic potential for many types of cancer cell lines 
(21-25). EGCG is thought to repress the growth of cancer cells directly through cell-cycle arrest (26), induction of apoptosis $(22,25)$, inhibition of metastasis (27), anti-angiogenesis (28) and activation of the immune function (29). These findings suggest that EGCG is an attractive potential agent for chemotherapy.

Several studies have demonstrated that induction of apoptosis in cancer cells could be a potential target for cancer treatment $(10,13)$. Apoptosis is a regulated mechanism leading cells to death through the extrinsic and the intrinsic pathways. The extrinsic pathway is triggered by Fas ligand (FasL), tumor necrosis factor (TNF) and tumor necrosis factor-related apoptosis-inducing ligand (TRAIL) binding to their respective receptors such as Fas, TNF receptor (TNFR), death receptor 4 (DR4; TRAIL-R1) and DR5 (TRAIL-R2) (30). Interaction of specific ligands with their receptors leads to activation of Fas-associated death domain (FADD) and caspases- 8 and -3 that is finally responsible for apoptosis (31). The intrinsic pathway is triggered by various stimuli such as DNA damage and chemotherapy agents. The intrinsic pathway involves disruption of the mitochondrial membrane environment and release of cytochrome $c$, Apaf-1, AIF, Endo G and procaspase- 9 into the cytosol followed by activation of caspases- 9 and -3 (32). Accumulating evidence indicates that heat shock protein 27 (HSP27) can regulate apoptosis through regulation of caspase activation $(33,34)$. HSP27 is induced by stress and its function includes protection from heat shock, hypertonic stress and oxidative stress (33). Recent studies have shown that HSP27 has been closely associated with AKT activity which contributes to inhibition of cell apoptosis (34).

A study of Rieger-Christ et al reported that EGCG exhibited growth inhibitory activity in human bladder carcinoma cell lines including the J82, UM-UC-3, EJ, KK47, T24 and TCCSUP cells (35). Also, Qin et al demonstrated that EGCG promoted apoptosis of T24 human bladder cancer cells through modulation of the PI3K/AKT pathway and Bcl-2 family proteins (36). However, the mechanism by which EGCG affects human urinary bladder carcinoma cells specific for Taiwanese patients has not yet been clarified. In the present study, we focused on the anti-cancer effects and molecular mechanisms of EGCG in the human bladder cancer TSGH8301 cells, a cell line derived from Taiwanese patients with urinary transitional cell carcinoma, in vivo and in vitro. We demonstrated that EGCG-induced apoptosis was carried out through AKT and the HSP27-modulated intrinsic apoptotic cascade pathways in TSGH-8301 cells.

\section{Materials and methods}

Chemicals and reagents. Epigallocatechin gallate (EGCG), dimethyl sulfoxide (DMSO), propidium iodide (PI), Triton X-100 and Trypan blue were obtained from Sigma-Aldrich Corp. (St. Louis, MO). RPMI-1640 medium, L-glutamine, fetal bovine serum (FBS), penicillin-streptomycin and trypsin-EDTA were obtained from Invitrogen Life Technologies (Carlsbad, CA). Caspase- 9 and -3 activity colorimetric assay kits, and a caspase-9 inhibitor (Z-LEHD-FMK) and a caspase-3 inhibitor (Z-DEVD-FMK) were obtained from R\&D Systems Inc. (Minneapolis, MN). The following primary antibodies were obtained: anti-caspase-9 and -3 (Cell Signaling Technology, Beverly, MA); anti-HSP27, cytochrome $c$, Apaf-1, p-AKT, AKT,
Bcl-2, Bax, BAD, p-BAD, actin and horseradish peroxidase (HRP)-linked goat anti-mouse IgG and goat anti-rabbit IgG, (Santa Cruz Biotechnology, Santa Cruz, CA, USA).

Cell culture. The human urinary bladder carcinoma cell line (TSGH-8301) specific for patients in Taiwan, was obtained from the Food Industry Research and Development Institute (Hsinchu, Taiwan). Cells were plated onto $75 \mathrm{~cm}^{2}$ tissue culture flasks with RPMI-1640 medium with $2 \mathrm{mM}$ L-glutamine containing $10 \% \mathrm{FBS}, 100 \mathrm{U} / \mathrm{ml}$ penicillin and $100 \mu \mathrm{g} / \mathrm{ml}$ streptomycin and grown at $37^{\circ} \mathrm{C}$ under a humidified $5 \% \mathrm{CO}_{2}$ atmosphere (37).

Mouse xenograft model in vivo. The BALB/c nu/nu athymic mice (5-week-old) were purchased (National Laboratory Animal Center, Taipei, Taiwan) and randomly divided into 4 groups of 10 mice each. At 6 weeks of age, mice were subcutaneously injected with TSGH-8301 cells $\left(1 \times 10^{7}\right)$ in Matrigel (BD Biosciences, San Jose, CA, USA) into the flanks of mice. After the tumor volume reached $200 \mathrm{~mm}^{3}$, mice were gavage fed with $100 \mu \mathrm{l}$ PBS (control) or $12.5,25$ and $50 \mathrm{mg} / \mathrm{kg} /$ day EGCG in $100 \mu \mathrm{l}$ PBS in each group. Tumor volume was monitored weekly based on the following formula: tumor volume $\left(\mathrm{mm}^{3}\right)=\mathrm{LxW}^{2} / 2$ (L: length and W: width). At the end of 6 weeks of gavage treatment, mice were euthanized via $\mathrm{CO}_{2}$ asphyxiation. Cancer tissues from each animal were removed, measured and weighed individually as previously described $(38,39)$. All animal studies were conducted according to institutional guidelines (Affidavit of Approval of Animal Use Protocol) approved by the Institutional Animal Care and Use Committee (IACUC) of China Medical University (Taichung, Taiwan).

\section{Cell morphology and viability determinations. TSGH-8301} cells $\left(2.5 \times 10^{5}\right.$ cells/well) grown in 24 -well plates were treated with EGCG at 0 and $75 \mu \mathrm{M}$ and incubated at $37^{\circ} \mathrm{C}$, $5 \% \mathrm{CO}_{2}$ and $95 \%$ air for $72 \mathrm{~h}$. Then cells were examined and photographed under a phase-contrast microscope as described previously $(40,41)$. Cells $\left(1 \times 10^{4}\right.$ cells/well) seeded onto 96 -well plates in $100 \mu \mathrm{l}$ were exposed to $0,25,50,75$ and $100 \mu \mathrm{M}$ of EGCG for 24, 48 and $72 \mathrm{~h}$. After EGCG incubation, MTT $(5 \mathrm{mg} / \mathrm{ml}, 10 \mu \mathrm{l})$ was added to each well and then cells were incubated at $37^{\circ} \mathrm{C}$ for $4 \mathrm{~h}$. The medium was carefully moved before $\sim 100 \mu \mathrm{l} 0.04 \mathrm{~N} \mathrm{HCl} /$ isopropanol were added and the absorbance at OD $570 \mathrm{~nm}$ was measured for each well. All results were performed from three independent experiments. The cell survival was shown as $\%$ of control $(42,43)$.

DNA content and analysis for the sub-G1 population by flow cytometry. Approximately $2.5 \times 10^{5}$ cells per well were seeded in 24-well plates and exposed to $75 \mu \mathrm{M}$ of EGCG for 24, 48 and 72 h. Cells were washed with PBS and fixed with $70 \%$ ethanol at $-20^{\circ} \mathrm{C}$ overnight. After being washed, cells were stained with $40 \mu \mathrm{g} / \mathrm{ml} \mathrm{PI,} \mathrm{0.1 \%} \mathrm{Triton} \mathrm{X-100} \mathrm{and} 100 \mu \mathrm{g} / \mathrm{ml}$ RNase A in a PBS solution for $30 \mathrm{~min}$. Each sample was analyzed and the fluorescence intensity of the DNA content was determined using a flow cytometer (FACSCalibur, Becton-Dickinson, Franklin Lakes, NJ, USA) as described elsewhere $(38,44)$.

Caspase-3/-9 activities and their specific inhibitors. The activities of caspase- 3 and -9 were measured by using caspase 
colorimetric assay kits according to the manufacturer's protocol (R\&D Systems Inc.). Briefly, cells ( $5 \times 10^{5}$ cells) were seeded in 6-well plates and exposed to $75 \mu \mathrm{M}$ of EGCG for $0,12,24,48$ and $72 \mathrm{~h}$ or control-treated before pretreatment without and with a caspase-9 inhibitor (Z-LEHD-FMK) or a caspase-3 inhibitor (Z-DEVD-FMK), respectively. Cells were harvested and lysed in $50 \mathrm{ml}$ lysis buffer. The supernatant containing the protein was incubated with the caspase-3 substrate (Ac-DEVD-pNA), caspase- 8 substrate (Ac-IETD-pNA) and caspase-9 substrate (Ac-LEHD-pNA), respectively in reaction buffer. All samples were incubated in 96 -well flat-bottom plates at $37^{\circ} \mathrm{C}$ for $1 \mathrm{~h}$. The amounts of released pNA were measured at a wavelength of $405 \mathrm{~nm}$ with ELISA reader $(13,42)$.

Assay for mitochondrial membrane potential $(\Delta \Psi m)$. Cells at a density of $2.5 \times 10^{5}$ cells were plated onto 24 -well plates and exposed to $75 \mu \mathrm{M}$ of EGCG for various periods of time $(0,6,12$ and $24 \mathrm{~h}$ ). Cells were then harvested, washed, and re-suspended in $500 \mu \mathrm{l}$ PBS with 50 nmole/l of 3,3'-dihexyloxacarbocyanine iodide (DiOC6, Invitrogen) at $37^{\circ} \mathrm{C}$ for $30 \mathrm{~min}$ to determine the level of $\Delta \Psi \mathrm{m}$. Cells were immediately measured by flow cytometry as previously described (45).

Western blotting analysis. TSGH-8301 cells $\left(\sim 1 \times 10^{7}\right)$ were treated with $75 \mu \mathrm{M}$ of EGCG for 0,24 and $48 \mathrm{~h}$ as well as exposed to various concentrations of $\operatorname{EGCG}(0,25,50,75$ and $100 \mu \mathrm{M})$ for $6 \mathrm{~h}$ of incubation. Cells were collected by centrifugation and the total proteins were collected by using the PRO-PREP ${ }^{\mathrm{TM}}$ protein extraction solution (iNtRON Biotechnology, Seongnam, Gyeonggi-Do, Korea). Equal amounts of protein lysate after determining the concentrations by the BCA assay (Pierce, Rockford, IL, USA) were run on a $10 \%$ SDS-PAGE gel and electrophoretically transferred to an Immobilon-P membrane (Millipore, Billerica, MA, USA) and probed with HSP27, cytochrome $c$, Apaf-1, caspase-9, caspase-3, p-AKT, AKT, Bcl-2, $\mathrm{Bax}, \mathrm{BAD}$, and p-BAD plus actin as an internal control. Bands were visualized via chemiluminescence (ECL detection kit, Millipore) using HRP-conjugated secondary antibodies. The image is the outcome of protein as described elsewhere (46-48).

AKT kinase assay. Instructions in the non-radioactive AKT kinase assay kit (Cell Signaling Technology) were followed to determine the in vitro AKT kinase activity in EGCG-treated TSGH-8301 cells. Briefly, cells were grown up to $70 \%$ confluency in a $10-\mathrm{cm}$ culture dish, and then treated for $6 \mathrm{~h}$ in the presence or absence of EGCG at 25, 50, 75 or $100 \mu \mathrm{M}$. Cells were harvested, washed with PBS and lysed in $1 \mathrm{X}$ cell lysis buffer. Immobilized AKT primary antibody bead slurry $(20 \mu \mathrm{l})$ was added to $200 \mu \mathrm{l}$ of whole-cell extract (200 $\mu \mathrm{g}$ of protein) overnight at $4^{\circ} \mathrm{C}$. Immunoprecipitates were washed three times with lysis buffer and twice with AKT kinase buffer. Kinase assays were performed in immuno-complexes (pellets) for $30 \mathrm{~min}$ at $30^{\circ} \mathrm{C}$ under continuous agitation in kinase buffer containing $200 \mu \mathrm{M}$ ATP, $1 \mu \mathrm{g}$ of glycogen synthase kinase-3 (GSK-3) of fusion protein. The kinase reaction was terminated by adding $20 \mu \mathrm{l}$ of $3 \mathrm{X}$ SDS sample buffer. The supernatant was saved for actin detection by immunoblotting to confirm that the same amount of whole cell extract was used and subjected to the monoclonal anti-AKT antibody. The protein level was quantified using the NIH ImageJ software and the activity was expressed as \% of control. Each experiment was performed in duplicate, and the assays were repeated three times.

Proteomic analysis. At a density of $1 \times 10^{7} \mathrm{TSGH}-8301$ cells in $75 \mathrm{~cm}^{2}$-flask were incubated with or without $75 \mu \mathrm{M}$ of EGCG for $6 \mathrm{~h}$ and then harvested for preparation as previously described (49). In the first dimension, isoelectric focusing (IEF) was performed with commercially available preformed immobilized $\mathrm{pH}$ gradients (IPGs) (linear $\mathrm{pH}$ gradient $3-10,13 \mathrm{~cm}$ ) by using an IPGphore IEF System (GE Healthcare Life Sciences, Piscataway, NJ, USA) with a three-phase program as previously described (49). Before second dimensional electrophoresis, the IPG gel strips were incubated at room temperature for $15 \mathrm{~min}$ and the gels were then submitted to a second dimension run on a Hoefer SE 600 (GE Healthcare Life Sciences) on running $12 \%$ SDS-PAGE gels $(16 \times 15 \mathrm{~cm})$, without stacking gels. The 2-D polyacrylamide gels were stained with Coomassie Brilliant Blue (CBB) to assign the protein $\mathrm{pI}$ and $\mathrm{MW}$, respectively. Data were considered significant when alterations were observed in at least two independent experiments (over five-fold up- or down-regulation) and the protein spots were consistently altered. Protein spots were quantified using the ImageMaster 2D Elite software (GE Healthcare Biosciences) as previously described (49). The procedures were modified as described by Kaji et al (50). Protein spots excised from the CBB-stained gel were destained and dried completely. The dried gels were rehydrated on ice for $45 \mathrm{~min}$ with a digestion buffer as previously described (49). Proteins were further digested at $37^{\circ} \mathrm{C}$ for 15 $\mathrm{h}$ after removing excess solution. The resultant peptides were extracted, desalted and concentrated using in-tip reverse phase resin as previously described (49). Peptides were isolated from each gel slice after in-gel digestion, desalted, and concentrated and peptide mixtures were eluted, applied to the sample target and air dried as previously described (49) and then the sample was analyzed in a nano-LC-MS/MS system. This analysis was performed on an integrated nano-LC-MS/MS system comprised of an LC Packings NanoLC system with an autosampler, and a QSTAR XL Q-Tof mass spectrometer (Applied Biosystems) fitted with nano-LC sprayer. Samples were first trapped and desalted on a LC Packings PepMap C18 $\mu$-Precolumn Cartidge after the peptides were eluted off from the precolumn and separated on an analytical LC Packings PepMap C18 column connected inline to the mass spectrometer as previously described $(49,51)$. The MS data were searched against the world wide web (WWW) search programs MS-Fit provided by http:// www.matrixscience.com/search_form_select.html with the NCBI database.

Statistical analysis. Differences between untreated controls and treated-groups were calculated by one-way analysis of variance (ANOVA) followed by the Dunnett's test. Results are presented as mean \pm standard deviation (SD) and are representative of three independent experiments. A p-value $<0.05$ was considered significant.

\section{Results}

Anti-tumor activity in vivo. We investigated the effects of EGCG on in vivo transplantation cancer cells growth for 42 days in a xenograft model. EGCG inhibited TSGH-8301 tumor growth 
A

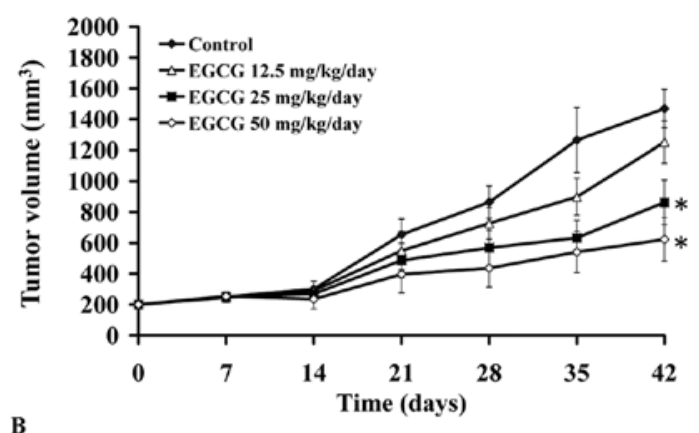

B

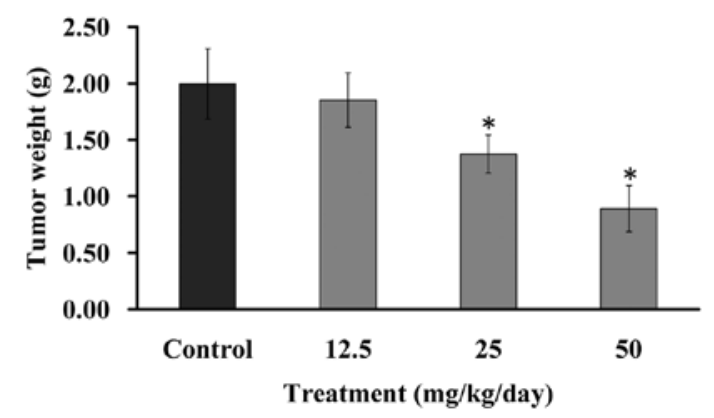

Figure 1. EGCG inhibits xenograft tumor growth in athymic mice. Human urinary bladder carcinoma TSGH-8301 cells $\left(1 \times 10^{7}\right)$ were injected subcutaneously into the flanks of male nude mice. Representative bearing xenograft solid tumor volume (A) and the effects of EGCG at $0,12.5,25$ and $50 \mathrm{mg} /$ $\mathrm{kg} / \mathrm{day}$ on tumor weight (B). Data are presented the mean $\pm \mathrm{SD}(\mathrm{n}=10)$ at $0-42$ days post-cancer implantation and ${ }^{*} \mathrm{p}<0.05$ was considered significant when compared with the control mice group.

in nude mice. EGCG was orally administered once every day at three different concentrations $(12.5,25$ and $50 \mathrm{mg} / \mathrm{kg})$. EGCG significantly reduced the tumor volume (Fig. 1A) and weight (Fig. 1B), respectively, in comparison of the control and EGCG-treated groups and these effects were dose-dependent responses.

EGCG causes morphological changes and growth inhibition in TSGH-8301 cells. The effects of treatment without and with EGCG on the morphological influences are shown in Fig. 2A. Our results indicate that TSGH-8301 cells exhibited clumping surface blebs and morphological shrinkage and rounding after exposure to $75 \mu \mathrm{M}$ for $72 \mathrm{~h}$. We then determined the cell growth inhibition effects and cell viability of EGCG in TSGH-8301 cells after treatment with $0,25,50,75$ and $100 \mu \mathrm{M}$ for 24,48 , $72 \mathrm{~h}$ exposure by using the MTT assay. As can be seen in Fig. $2 \mathrm{~B}$, the cell viability was significant decreased in a dose- and time-dependent manner in EGCG-treated TSGH-8301 cells. The half maximal inhibitory concentration $\left(\mathrm{IC}_{50}\right)$ in TSGH8301 cells for $48 \mathrm{~h}$ exposure is close to $75 \mu \mathrm{M}$ which was used for further experiments and assays in this study.

EGCG induces apoptosis in TSGH-8301 cells. Cells were treated with $75 \mu \mathrm{M}$ of EGCG for 0,24 and $72 \mathrm{~h}$, and the DNA content for cell cycle distribution was analyzed by flow cytometry.EGCG-triggered cytotoxicity in TSGH-8301 cells may be mediated through induction of apoptosis and regulation of its signaling cascades. Flow cytometric profiles demonstrated that EGCG at $75 \mu \mathrm{M}$ is able to increase the sub-G1 group in treated TSGH-8301 cells after 48 and $72 \mathrm{~h}$ of treatment (Fig. 3A). In
A

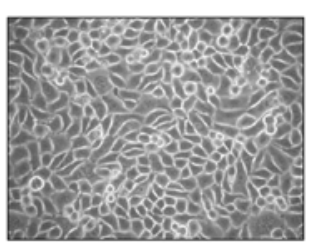

Control

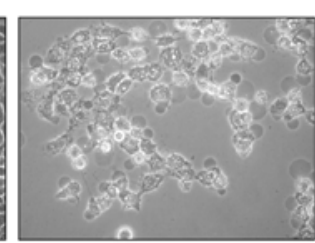

EGCG $(75 \mu \mathrm{M} ; 72 \mathrm{~h})$
B

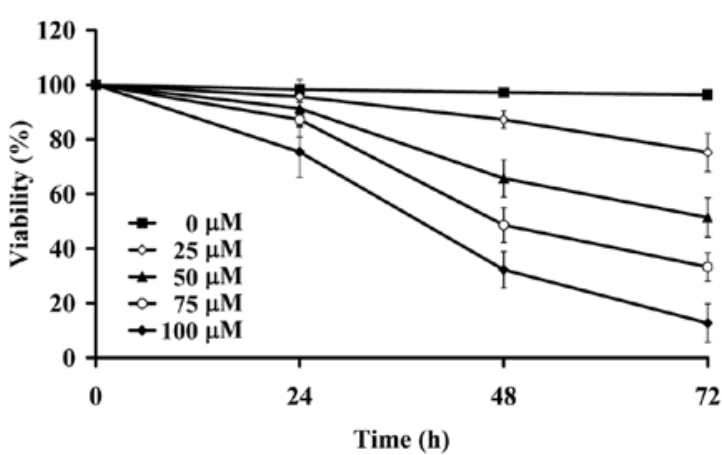

Figure 2. EGCG causes the morphological changes and inhibits cell viability in the human urinary bladder carcinoma TSGH-8301 cells. Cells after treatment with or without $75 \mu \mathrm{M}$ of EGCG for $72 \mathrm{~h}$ were examined and photographed by a phase-contrast microscope at a magnification of x200 (A). Cells were exposed to $0,25,50,75$ and $100 \mu \mathrm{M}$ of EGCG for $24,48,72 \mathrm{~h}$ and then harvested for determination the percentage of viable cells using the MTT assay as described in Materials and methods.
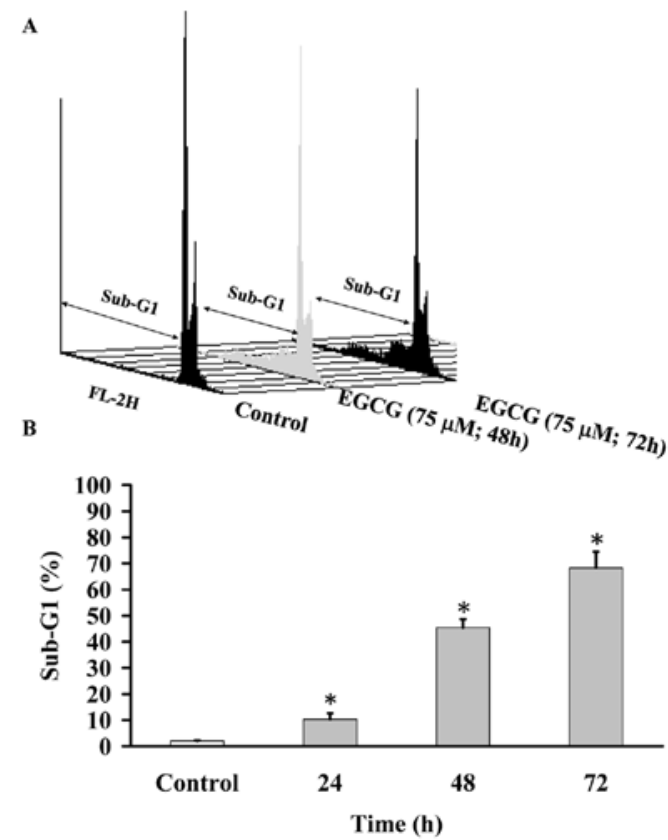

Figure 3. EGCG-induced apoptosis (sub-G1 population) is examined by flow cytometry in TSGH-8301 cells. Cells exposed to $75 \mu \mathrm{M}$ of EGCG for $0,24,48$ and $74 \mathrm{~h}$ were harvested for examining DNA content for cell cycle distribution by using a flow cytometer. Respective profile analyzed form BD CellQuest Pro software was indicated for determining sub-G1 groups (A), which is quantified and shown in panel (B) as described in Materials and methods. Each point is the mean $\pm \mathrm{SD}$ of three independent experiments. " $\mathrm{p}<0.05$, is significantly different compared with the untreated control.

addition, the sub-G1 populations showed significant increases in EGCG-treated TSGH-8301 cells after 24, 48 and $72 \mathrm{~h}$ of incubation and these effects were time-dependent (Fig. 3B). 


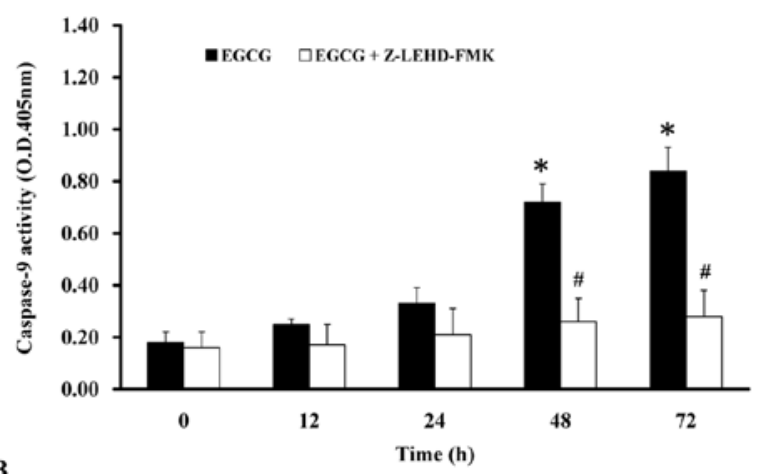

B

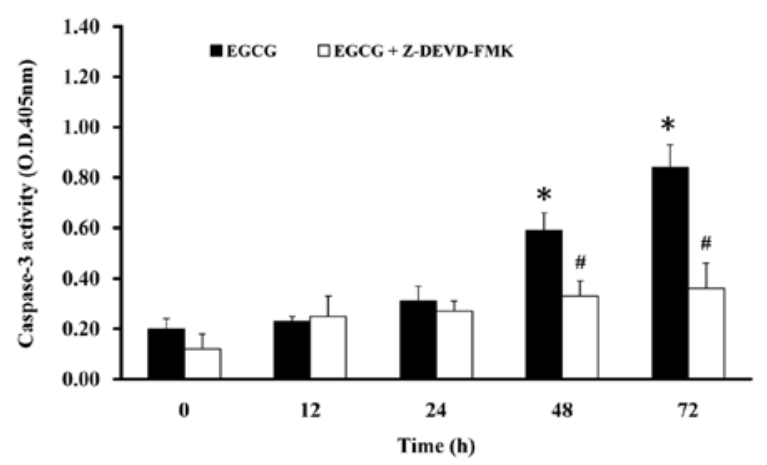

Figure 4. EGCG stimulation of the caspase-9 and -3 activities and effects of their specific inhibitors in TSGH-8301 cells. Cells were treated with $75 \mu \mathrm{M}$ of EGCG for 12, 24, 48 and $72 \mathrm{~h}$ and then the whole-cell lysate was subjected to caspase-9 (A) and -3 (B) activity assays, respectively. The caspase-9 inhibitor (Z-LEHD-FMK) and the caspase-3 inhibitor (Z-DEVD-FMK) were used to decrease the caspase activities. Data are expressed as the mean \pm SD of three independent experiments. ${ }^{*} \mathrm{p}<0.05$, significantly different compared with the untreated group $(0 \mathrm{~h}) .{ }^{*} \mathrm{p}<0.05$, significantly different compared to the EGCG 48 or $72 \mathrm{~h}$ treatment groups.

EGCG stimulates caspase-9 and -3 activities in TSGH-8301 cells. To investigate the EGCG-induced apoptotic effects in TSGH-8301 cells, cells were incubated with $75 \mu \mathrm{M}$ EGCG for 12, 24, 48 and $72 \mathrm{~h}$ and the activities of caspase- 9 and -3 were determined by caspase -9 and -3 colorimetric assay kits, respectively. Treatment of TSGH-8301 cells with EGCG caused an increase of caspase- 9 and -3 activities after 48 and $72 \mathrm{~h}$ of treatment (Fig. 4). To confirm the mechanisms of EGCG-induced apoptosis, cells were pretreated with a caspase-9 inhibitor (Z-LEHD-FMK) and a caspase-3 inhibitor (Z-DEVD-FMK) for $1 \mathrm{~h}$ and exposed to $75 \mu \mathrm{M}$ of EGCG for 12-72 $\mathrm{h}$ in TSGH-8301 cells. Results demonstrated that Z-LEHD-FMK and Z-DEVD-FMK are able to attenuate the EGCG-stimulated caspase-9 and -3 activities, respectively, in TSGH-8301 cells (Fig. 4). Therefore, our results suggest that mitochondrial dysfunction-mediated caspase- 9 and -3 activation may be involved in the EGCG-provoked apoptotic death in TSGH-8301 cells.

EGCG increases the loss of $\Delta \Psi_{m}$ and its associated protein levels. We next investigated whether or not EGCG-induced apoptosis is based on the mitochondria-dependent intrinsic cascade pathway. Cells were harvested for examining the level of $\Delta \Psi \mathrm{m}$ after exposure to EGCG for various intervals of time. EGCG increased the loss of $\Delta \Psi \mathrm{m}$ in TSGH-8301 cells (Fig. 5A). Therefore, we further investigated whether EGCG
A
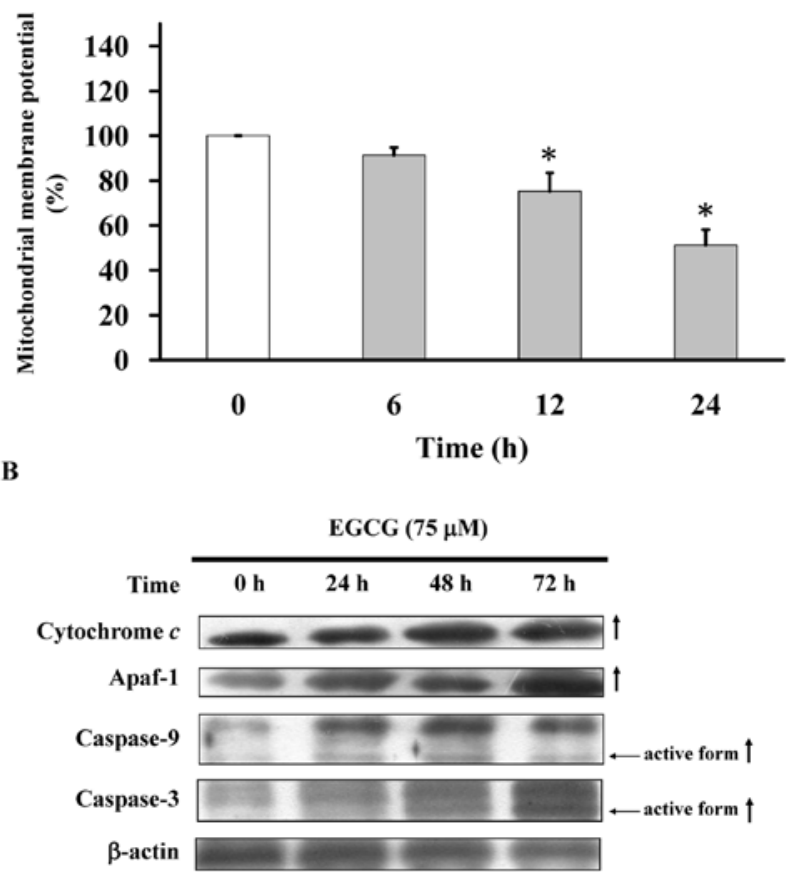

Figure 5. EGCG decreases the level of mitochondrial membrane potential $(\Delta \Psi \mathrm{m})$ and alters apoptosis-associated protein levels in TSGH-8301 cells. Cells were incubated with $75 \mu \mathrm{M}$ of EGCG for $0,6,12$ and $24 \mathrm{~h}$ and then stained with DiOC6 for measuring the level of $\Delta \Psi_{\mathrm{m}}$ by flow cytometry (A). EGCG affected mitochondria-dependent apoptotic relative protein levels in TSGH-8301 cells for $0,24,48$ and 72-h exposures for determining cytochrome $c$, Apaf-1, caspase- 9 and -3 by Western blotting (B) as described in Materials and methods.

induced apoptosis of TSGH-8301 cells through the mitochondrial and intrinsic signaling pathways. Cells were treated with $75 \mu \mathrm{M}$ of EGCG for 24, 48 and $72 \mathrm{~h}$ before analysis of protein levels by Western blotting. EGCG increased the protein levels of cytochrome c, Apaf-1, caspase-9 and -3 (Fig. 5B) in TSGH8301 cells. Hence, this study suggests that EGCG-induced apoptotic death of TSGH-8301 cells is mediated through the mitochondrial and intrinsic cascade pathways.

Proteomics analysis for EGCG-induced apoptosis in TSGH8301 cells. To explore the upstream molecular mechanisms of EGCG-induced apoptosis, the treatment condition with EGCG for $6 \mathrm{~h}$ was selected for the proteomic analysis. A pair of representative 2-D gel images for whole cell proteins extracted from TSGH-8301 cells with EGCG treatments for $6 \mathrm{~h}$ and control cells can be seen in Fig. 6. Proteins were separated in the 2-D gels in the ranges of MW 14-100 kDa and pI 3-10. Image analysis revealed that a number of protein spots were significantly altered in terms of volume intensity. Highlighted in circles are the locations where protein alterations were detected. Table I lists the spot number, protein name, accession number, molecular weights, pIs, and sequence coverage from the programs MS-Fit. These altered proteins include the significant down-regulation of HSP27, porin (mitochondrial protein), tropomyosin 3 isoform 2, prohibitin (mitochondrial protein) and up-regulation of keratin 5, 14 and 17. Our data suggest that HSP27 and mitochondria may be involved in the major target of EGCG cytotoxicity in TSGH-8301 cells. 
Table I. Summary of protein-database search results.

\begin{tabular}{|c|c|c|c|c|c|}
\hline Sample no. & Protein name & Accession no. & $\mathrm{pI}$ & MW (Da) & Seq. coverage \\
\hline 1 & Porin & gil190200 & 6.32 & 38069 & $28 \%$ \\
\hline 2 & Tropomyosin 3 isoform 2 & gil24119203 & 4.75 & 29015 & $32 \%$ \\
\hline 3 & Prohibitin & gil4505773 & 5.57 & 29786 & $7 \%$ \\
\hline 4 & Heat shock protein 27 & gil662841 & 7.83 & 22313 & $41 \%$ \\
\hline 5 & Keratin 5 & gil18999435 & 7.59 & 62340 & $27 \%$ \\
\hline 6 & Keratin 14 & gil12803709 & 5.09 & 51619 & $44 \%$ \\
\hline 7 & Keratin 17 & gil4557701 & 4.97 & 48076 & $40 \%$ \\
\hline
\end{tabular}
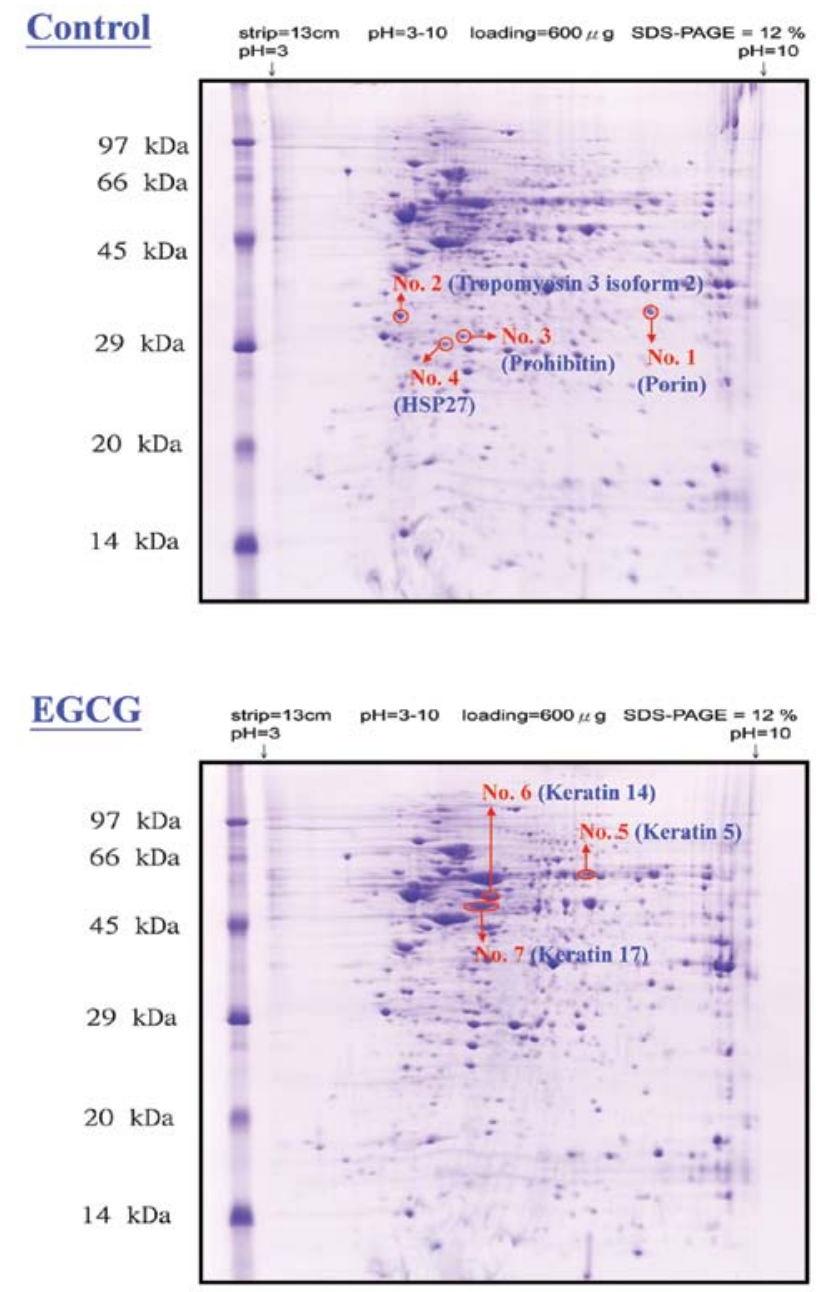

Figure 6. Overview of the 2-D gel images from extracts of TSGH-8301 cells Spots highlighted in circles are the areas where significant and consistent differences were expressed in the protein expression levels in EGCG-untreated (Control, top) and treated (bottom) TSGH-8301 cells.

EGCG alters HSP27, $p$-AKT, Bcl-2, Bax, BAD and $p-B A D$ protein levels as well as reduces AKT kinase activity in TSGH8301 cells. To explore the upstream molecular mechanisms of EGCG-induced apoptosis, we evaluated the effect of EGCG on the HSP27, p-AKT, Bcl-2, Bax, BAD and p-BAD protein levels and AKT kinase activity in cell system. Western blot analysis identified reduction of HSP27 and phospho-AKT as molecular determinants of EGCG-induced apoptosis in TSGH-8301 cells
A

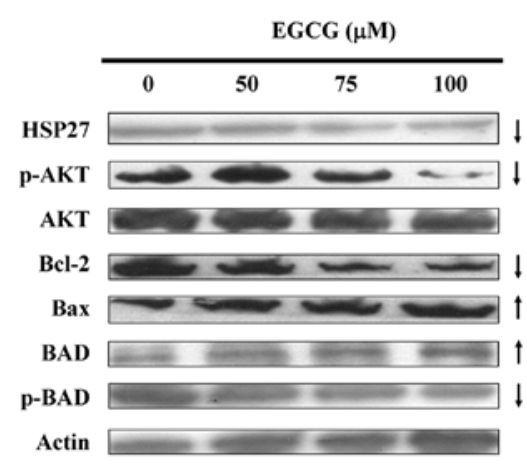

B

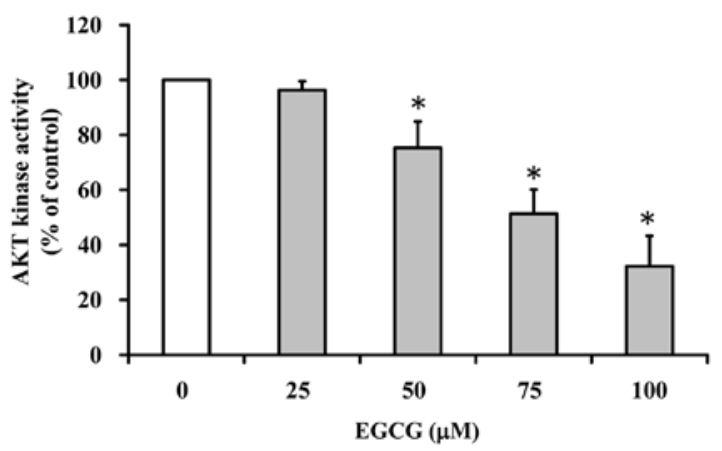

Figure 7. EGCG affects AKT and Bcl-2 family related protein levels in TSGH8301 cells, and decreases AKT kinase activity. Cells were exposed to 50,75 and $100 \mu \mathrm{M}$ of EGCG for $6 \mathrm{~h}$ and then total protein lysates were used for the detections of HSP27, p-AKT, AKT, Bcl-2, Bax, BAD and p-BAD protein levels by Western blotting (A) as described in Materials and methods. Cells were treated with different concentrations of EGCG for $6 \mathrm{~h}$ and then harvested for examination of the AKT activity following the manufacturer's protocol (B). Results are shown as means $\pm \mathrm{SD}$ of three independent experiments. " $\mathrm{p}<0.05$ indicates a significant difference when compared with the untreated group $(0 \mu \mathrm{M})$.

in a dose-dependent manner (Fig. 7A). Thus, these results suggest that EGCG-triggered apoptosis is involved in the decrease of the protein levels in HSP27 and p-AKT in TSGH8301 cells. It has been reported that the pro-apoptotic protein $\mathrm{BAD}$, a member of the Bcl-2 family, is rendered inactive when the phosphorylated serine/threonine protein kinase $\mathrm{p}$-AKT converts p-BAD and BAD $(52,53)$. To investigate the downstream effectors, we traced the phosphorylation status of BAD and also assessed the protein levels of Bcl-2 family, including Bcl-2, Bax and BAD in EGCG-treated TSGH-8301 cells with $0,50,75$ and $100 \mu \mathrm{M}$ for $24-\mathrm{h}$ exposure. Western blotting illustrated that EGCG decreased the levels of p-AKT, AKT, Bcl-2 


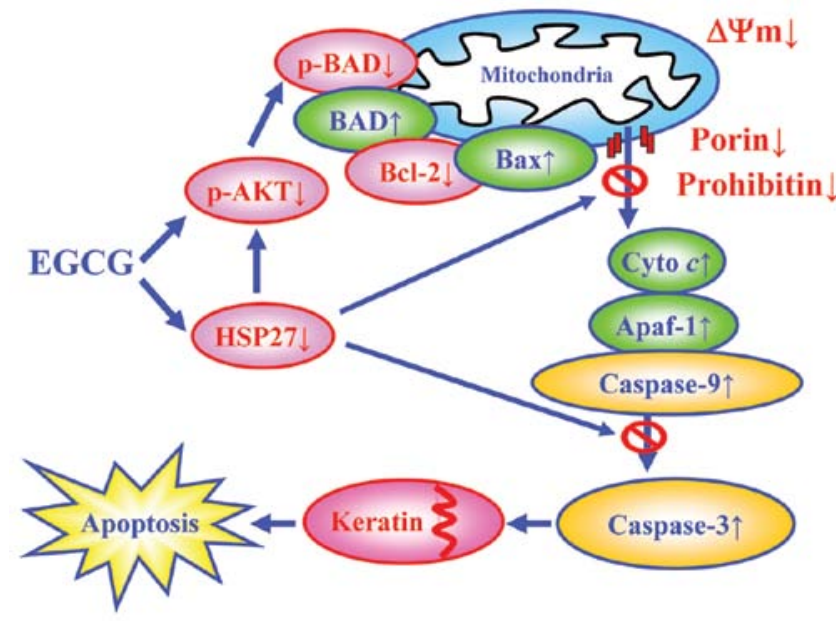

Figure 8. Illustration of the proposed signaling pathways of the EGCGtriggered apoptotic death and its modulated upstream HSP27/AKT signal in human urinary bladder carcinoma TSGH-8301 cells.

and $\mathrm{p}-\mathrm{BAD}$ rather than increased the protein levels of Bax and BAD proteins in TSGH-8301 cells (Fig. 7A). Based on these results, apoptosis of TSGH-8301 cells appears to be mediated through increasing the ratio of $\mathrm{Bax} / \mathrm{BAD} / \mathrm{Bcl}-2$ level after EGCG exposure. Moreover, TSGH-8301 cells were harvested after treatment with $0,25,50,75$ and $100 \mu \mathrm{M}$ of EGCG for $6 \mathrm{~h}$ to measure AKT activity. Our results reveal that EGCG down-regulated the AKT activity after 50-100 $\mu \mathrm{M}$ EGCG for $6 \mathrm{~h}$ of treatment and this inhibition was time-dependent (Fig. 7B). We suggest that these responses are involved in the suppression of AKT activity, which may be regulated by p-BAD. These results signify the involvement of the HSP27/ AKT/BAD survival pathway in the EGCG-induced apoptotic death of TSGH-8301 cells.

\section{Discussion}

Many studies have reported that EGCG has growth inhibitory effects in human cancer cell lines (21-27,54,55), but few have addressed its inhibitory effects on Taiwan-specific human urinary bladder carcinoma cells. In this study, we examined the cytotoxicity of EGCG in TSGH-8301 cells in vitro and examined EGCG-affected TSGH-8301 cells in vivo. Our data indicate that EGCG inhibited xenograft tumor size of TSGH-8301 cells in a nude mouse model in vivo (Fig. 1). On the other hand, EGCG at 25-100 $\mu \mathrm{M}$ could have significant cytotoxicity effects on TSGH-8301 cells in vitro (Fig. 2). Our previous study revealed that EGCG exerts low cytotoxicity on normal cells such as Detroit 551 normal human cell line (13). Our data suggest that EGCG represents a promising candidate as an anti-urinary bladder carcinoma agent with low toxicity to normal cells.

In this study, we have shown that EGCG triggered morphological changes (Fig. 2) and reduced the cell viability in TSGH-8301 cells in a dose- and time-dependent manner. EGCG induced accumulation of the sub-G1 population (apoptosis, Fig. 3). Moreover, our results demonstrate that EGCG significantly promoted activities of caspase-9 (Fig. 4A) and caspase-3 (Fig. 4B) after 24-72 h treatment, but there was no significant effect in caspase-8 activity (data not shown). EGCG increased the protein levels of Bax and BAD, and inhibited the level of Bcl-2 (Fig. 7A) which led to the disruption of $\Delta \Psi \mathrm{m}$ (Fig. 5A) and the release of cytochrome $\mathrm{c}$, AIF and pro-caspase-9 (Fig. 5B). Furthermore, EGCG reduced the levels of porin (the voltage-dependent anion channel, regulating the mitochondrial response to certain cell death stimuli) and prohibitin (stabilization of mitochondrial function) by proteomic analysis (Fig. 6 and Table I). EGCG increased caspase-9 and -3 activities (Fig. 4), and pretreatment with caspase- 9 and -3 inhibitors led to decreased caspase- 9 and -3 activities, resulting in keratin cleavage (Figs. 4 and 6). Qin et al demonstrated that EGCG promotes apoptosis in T24 human bladder cancer cells through modulation of the PI3K/AKT pathway and Bcl-2 family proteins (36). It has been reported that $\mathrm{AKT}$ is involved in the survival signaling pathway by phosphorylating BAD $(56,57)$. In the present study, EGCG inhibited the activity of AKT in TSGH-8301 cells (Fig. 7B), leading to that BAD was dephosphorylated and then induced apoptosis in EGCG-treated TSGH-301 cells. Our results suggest that the intrinsic pathway is the major pathway of EGCG-induced apoptosis in TSGH-8301 cells. Several studies have reported that EGCG induces cell apoptosis through the extrinsic apoptotic pathway in HepG2 and U937 cells $(58,59)$. In our previously studies, we also demonstrated that EGCG-induced apoptosis is mainly mediated by induction of the extrinsic and intrinsic pathways in human adrenal cancer NCI-H295 cells (13). Of note, EGCG-provoked cell death occurs through various apoptotic signaling pathways in different types of tumor cell lines in vitro.

EGCG could be developed as a new class of chemopreventive or chemotherapeutic agent for cancer because it targets multiple pathways and resulted in inhibition of cancer cell growth $(13,58-60)$. Recent studies suggest that EGCG may affect many important signaling pathways, including epidermal growth factor receptor (EGFR), insulin-like growth factor receptor (IGFR), vascular endothelial growth factor receptor (VEGFR), mitogen-activated protein kinase (MAPK), nuclear factor $-\kappa \mathrm{B}(\mathrm{NF}-\kappa \mathrm{B})$, phosphatidylinositol 3-kinase (PI3K)/AKT and heat shock protein $27(33,34,61)$. In this study, we initially demonstrated that EGCG significantly suppressed HSP27 protein level in TSGH-8301 cells by Western blotting and proteomic analyses (Figs. 6 and 7). HSP27 (an actin-binding protein) is a stress-inducible protein that prevents apoptosis induced by anticancer agents $(33,34)$. HSP27 is associated with the regulation of F-actin assembly and is a known regulator of AKT $(33,34)$. Konishi et al have shown that in COS-7 cells treated with $\mathrm{H}_{2} \mathrm{O}_{2}$, AKT is activated and the association of HSP27 with AKT increases concurrently with the enhancement of AKT activity (62). Natsume et al have reported that EGCG induced suppression of the AKT cascade in osteoblasts contributes to the modulation of osteoblastic cell function toward bone formation via specifically down-regulating HSP27 induction (63). This evidence suggests that HSP27 could regulate AKT activity. However, another report has demonstrated that HSP27 directly inhibits caspase-9 and -3 activation and reduces apoptosome formation (64). Our results showed that when expressed to EGCG in TSGH-8301 cells, HSP27, markedly decreased protein levels (Fig. 7A), induced the leakage of cytochrome $c$, Apaf-1 and 
pro-caspase-9 (Fig. 2A), exhibited caspase- 9 and -3 activation (Fig. 4), and significantly improved cell apoptosis (Figs. 2A and 3). Our results suggest that HSP27 could either directly or indirectly induce apoptosis in EGCG-treated TSGH-8301 cells. The direct effect is that HSP27 inhibits caspase- 9 and -3 activation and reduces apoptosome formation. The indirect effect is that HSP27 regulates BAD phosphorylation by altering the AKT kinases activity.

In conclusion, in vivo results indicate that the EGCG effects in the TSGH-8301 xenograft tumor model of human urinary bladder carcinoma was due to its anti-tumor activity. The proposed model of EGCG mechanism of action for apoptosis in TSGH-8301 cells is shown in Fig. 8. EGCG-induced apoptosis in TSGH-8301 cells is mediated through the HSP27 and AKT pathways, which involve BAD phosphorylation and activation of caspase- 9 and -3 . Proteomic results and mitochondrial functional studies confirm that the intrinsic pathway is the major apoptotic pathway of EGCG in TSGH-8301 cells. EGCG deserves further investigation in preclinical studies or in a clinical trial as a potential anti-urinary bladder carcinoma agent.

\section{Acknowledgements}

The study was supported by a research grant from the National Science Council, Republic of China (Taiwan) (NSC 97-2320-B-039-004-MY3) awarded to J.-S.Y. We further acknowledge the supports by the grants from China Medical University (CMU99-S-08) and China Medical University Hospital (DMR-95-111). Mass spectrometric analyses were performed by the Proteomics Core Laboratory, Office of Research and Development at China Medical University, Taichung, Taiwan, R.O.C.

\section{References}

1. Porter MP and Penson DF: Health related quality of life after radical cystectomy and urinary diversion for bladder cancer: a systematic review and critical analysis of the literature. J Urol 173: 1318-1322, 2005.

2. Kuo JH, Chu YL, Yang JS, et al: Cantharidin induces apoptosis in human bladder cancer TSGH 8301 cells through mitochondriadependent signal pathways. Int J Oncol 37: 1243-1250, 2010.

3. Natrajan R, Louhelainen J, Williams S, Laye J and Knowles MA: High-resolution deletion mapping of 15q13.2-q21.1 in transitional cell carcinoma of the bladder. Cancer Res 63: 7657-7662, 2003.

4. Zapatero A, Martin de Vidales C, Arellano R, Bocardo G, Perez $\mathrm{M}$ and Rios P: Updated results of bladder-sparing trimodality approach for invasive bladder cancer. Urol Oncol 28: 368-374, 2010

5. Kotwal S and Munro N: Radiotherapy in localized bladder cancer: what is the evidence? Curr Opin Urol 20: 426-431, 2010.

6. Wirth M, Plattner VE and Gabor F: Strategies to improve drug delivery in bladder cancer therapy. Expert Opin Drug Deliv 6: 727-744, 2009.

7. Dhote R, Beuzeboc P, Thiounn N, et al: High incidence of brain metastases in patients treated with an M-VAC regimen for advanced bladder cancer. Eur Urol 33: 392-395, 1998.

8. Fujii H, Nishioka H, Wakame K, Magnuson BA and Roberts A: Acute, subchronic and genotoxicity studies conducted with Oligonol, an oligomerized polyphenol formulated from lychee and green tea extracts. Food Chem Toxicol 46: 3553-3562, 2008

9. Siddiqui IA, Adhami VM, Bharali DJ, et al: Introducing nanochemoprevention as a novel approach for cancer control: proof of principle with green tea polyphenol epigallocatechin-3-gallate. Cancer Res 69: 1712-1716, 2009.
10. Li Y, Yuan YY, Meeran SM and Tollefsbol TO: Synergistic epigenetic reactivation of estrogen receptor-alpha (ERalpha) by combined green tea polyphenol and histone deacetylase inhibitor in ERalpha-negative breast cancer cells. Mol Cancer 9: 274, 2010.

11. Zhang M, Zhao X, Zhang X and Holman CD: Possible protective effect of green tea intake on risk of adult leukaemia. Br J Cancer 98: 168-170, 2008.

12. Sueoka N, Suganuma M, Sueoka E, et al: A new function of green tea: prevention of lifestyle-related diseases. Ann NY Acad Sci 928: 274-280, 2001.

13. Wu PP, Kuo SC, Huang WW, et al: (-)-Epigallocatechin gallate induced apoptosis in human adrenal cancer NCI-H295 cells through caspase-dependent and caspase-independent pathway. Anticancer Res 29: 1435-1442, 2009.

14. Azam S, Hadi N, Khan NU and Hadi SM: Prooxidant property of green tea polyphenols epicatechin and epigallocatechin3-gallate: implications for anticancer properties. Toxicol In vitro 18: 555-561, 2004.

15. Roura E, Andres-Lacueva C, Estruch R, Lourdes Mata Bilbao M, Izquierdo-Pulido $\mathrm{M}$ and Lamuela-Raventos RM: The effects of milk as a food matrix for polyphenols on the excretion profile of cocoa (-)-epicatechin metabolites in healthy human subjects. Br J Nutr 100: 846-851, 2008

16. Hara Y, Fujino M, Takeuchi M and Li XK: Green-tea polyphenol (-)-epigallocatechin-3-gallate provides resistance to apoptosis in isolated islets. J Hepatobiliary Pancreat Surg 14: 493-497, 2007.

17. Wheeler DS, Catravas JD, Odoms K, Denenberg A, Malhotra V and Wong HR: Epigallocatechin-3-gallate, a green tea-derived polyphenol, inhibits IL-1 beta-dependent proinflammatory signal transduction in cultured respiratory epithelial cells. J Nutr 134: 1039-1044, 2004.

18. Bose M, Lambert JD, Ju J, Reuhl KR, Shapses SA and Yang CS: The major green tea polyphenol, (-)-epigallocatechin-3-gallate, inhibits obesity, metabolic syndrome, and fatty liver disease in high-fat-fed mice. J Nutr 138: 1677-1683, 2008.

19. Levites Y, Amit T, Mandel S and Youdim MB: Neuroprotection and neurorescue against $\mathrm{A} \beta$ toxicity and PKC-dependent release of nonamyloidogenic soluble precursor protein by green tea polyphenol (-)-epigallocatechin-3-gallate. FASEB J 17: 952-954, 2003.

20. Siddiqui IA, Malik A, Adhami VM, et al: Green tea polyphenol EGCG sensitizes human prostate carcinoma LNCaP cells to TRAIL-mediated apoptosis and synergistically inhibits biomarkers associated with angiogenesis and metastasis. Oncogene 27: 2055-2063, 2008.

21. Peng G, Wargovich MJ and Dixon DA: Anti-proliferative effects of green tea polyphenol EGCG on Ha-Ras-induced transformation of intestinal epithelial cells. Cancer Lett 238: 260-270, 2006.

22. Collins QF, Liu HY, Pi J, Liu Z, Quon MJ and Cao W: Epigallocatechin-3-gallate (EGCG), a green tea polyphenol, suppresses hepatic gluconeogenesis through 5'-AMP-activated protein kinase. J Biol Chem 282: 30143-30149, 2007.

23. Guo S, Yang S, Taylor $\mathrm{C}$ and Sonenshein GE: Green tea polyphenol epigallocatechin-3 gallate (EGCG) affects gene expression of breast cancer cells transformed by the carcinogen 7,12-dimethylbenz[a]anthracene. J Nutr 135: S2978-S2986, 2005.

24. Annabi B, Currie JC, Moghrabi A and Beliveau R: Inhibition of HuR and MMP-9 expression in macrophage-differentiated HL-60 myeloid leukemia cells by green tea polyphenol EGCG. Leuk Res 31: 1277-1284, 2007.

25. Liu L, Lai CQ, Nie L, et al: The modulation of endothelial cell gene expression by green tea polyphenol-EGCG. Mol Nutr Food Res 52: 1182-1192, 2008.

26. Nishikawa T, Nakajima T, Moriguchi M, et al: A green tea polyphenol, epigalocatechin-3-gallate, induces apoptosis of human hepatocellular carcinoma, possibly through inhibition of Bcl-2 family proteins. J Hepatol 44: 1074-1082, 2006.

27. Miyake H, Hara I, Yamanaka K, Gohji K, Arakawa S and Kamidono S: Overexpression of Bcl-2 enhances metastatic potential of human bladder cancer cells. Br J Cancer 79: 1651-1656, 1999.

28. Sagara Y, Miyata Y, Nomata K, Hayashi T and Kanetake H: Green tea polyphenol suppresses tumor invasion and angiogenesis in N-butyl-(-4-hydroxybutyl) nitrosamine-induced bladder cancer. Cancer Epidemiol 34: 350-354, 2010.

29. Gillespie K, Kodani I, Dickinson DP, et al: Effects of oral consumption of the green tea polyphenol EGCG in a murine model for human Sjogren's syndrome, an autoimmune disease. Life Sci 83: 581-588, 2008. 
30. Jacquemin G, Shirley S and Micheau O: Combining naturally occurring polyphenols with TNF-related apoptosis-inducing ligand: a promising approach to kill resistant cancer cells? Cell Mol Life Sci 67: 3115-3130, 2010.

31. von Haefen C, Wendt J, Semini G, et al: Synthetic glycosidated phospholipids induce apoptosis through activation of FADD, caspase- 8 and the mitochondrial death pathway. Apoptosis 16: 636-651 2011.

32. De Martino L,Marfe G,Longo M, et al: Bid cleavage, cytochrome $c$ release and caspase activation in canine coronavirus-induced apoptosis. Vet Microbiol 141: 36-45, 2010.

33. Tan CY, Ban H, Kim YH and Lee SK: The heat shock protein 27 (Hsp27) operates predominantly by blocking the mitochondrialindependent/extrinsic pathway of cellular apoptosis. Mol Cells 27: 533-538, 2009.

34. Rane MJ, Pan Y, Singh S, et al: Heat shock protein 27 controls apoptosis by regulating Akt activation. J Biol Chem 278: 27828-27835, 2003.

35. Rieger-Christ KM, Hanley R, Lodowsky C, et al: The green tea compound, (-)-epigallocatechin-3-gallate downregulates $\mathrm{N}$-cadherin and suppresses migration of bladder carcinoma cells. J Cell Biochem 102: 377-388, 2007.

36. Qin J, Xie LP, Zheng XY, et al: A component of green tea, (-)-epigallocatechin-3-gallate, promotes apoptosis in T24 human bladder cancer cells via modulation of the PI3K/Akt pathway and Bcl-2 family proteins. Biochem Biophys Res Commun 354: 852-857, 2007

37. Lu KH, Lue KH, Chou MC and Chung JG: Paclitaxel induces apoptosis via caspase-3 activation in human osteogenic sarcoma cells (U-2 OS). J Orthop Res 23: 988-994, 2005.

38. Ji BC, Hsu WH, Yang JS, et al: Gallic acid induces apoptosis via caspase-3 and mitochondrion-dependent pathways in vitro and suppresses lung xenograft tumor growth in vivo. J Agric Food Chem 57: 7596-7604, 2009.

39. Dethlefsen LA, Prewitt JM and Mendelsohn ML: Analysis of tumor growth curves. J Natl Cancer Inst 40: 389-405, 1968.

40. Lin CC, Yang JS, Chen JT, et al: Berberine induces apoptosis in human HSC-3 oral cancer cells via simultaneous activation of the death receptor-mediated and mitochondrial pathway. Anticancer Res 27: 3371-3378, 2007.

41. Chen YC, Lu PH, Pan SL, et al: Quinolone analogue inhibits tubulin polymerization and induces apoptosis via Cdk1-involved signaling pathways. Biochem Pharmacol 74: 10-19, 2007.

42. Lin SS, Huang HP, Yang JS, et al: DNA damage and endoplasmic reticulum stress mediated curcumin-induced cell cycle arrest and apoptosis in human lung carcinoma A-549 cells through the activation caspases cascade- and mitochondrial-dependent pathway. Cancer Lett 272: 77-90, 2008.

43. Lu HF, Wang HL, Chuang YY, et al: Danthron induced apoptosis through mitochondria- and caspase-3-dependent pathways in human brain glioblastoma multiforms GBM 8401 cells. Neurochem Res 35: 390-398, 2010.

44. Wu SH, Hang LW, Yang JS, et al: Curcumin induces apoptosis in human non-small cell lung cancer NCI-H460 cells through ER stress and caspase cascade- and mitochondria-dependent pathways. Anticancer Res 30: 2125-2133, 2010.

45. Lu CC, Yang JS, Huang AC, et al: Chrysophanol induces necrosis through the production of ROS and alteration of ATP levels in J5 human liver cancer cells. Mol Nutr Food Res 54: 967-976, 2010.

46. Yang JS, Hour MJ, Huang WW, Lin KL, Kuo SC and Chung JG: MJ-29inhibits tubulin polymerization, induces mitotic arrest, and triggers apoptosis via cyclin-dependent kinase 1-mediated Bcl-2 phosphorylation in human leukemia U937 cells. J Pharmacol Exp Ther 334: 477-488, 2010.

47. Chiang JH, Yang JS, Ma CY, et al: Danthron, an anthraquinone derivative, induces DNA damage and caspase cascades-mediated apoptosis in SNU-1 human gastric cancer cells through mitochondrial permeability transition pores and Bax-triggered pathways. Chem Res Toxicol 24: 20-29, 2011.
48. Lu HF, Lai KC, Hsu SC, et al: Curcumin induces apoptosis through FAS and FADD, in caspase-3-dependent and -independent pathways in the N18 mouse-rat hybrid retina ganglion cells. Oncol Rep 22: 97-104, 2009.

49. Chung JG, Yang JS, Huang LJ, et al: Proteomic approach to studying the cytotoxicity of YC-1 on U937 leukemia cells and antileukemia activity in orthotopic model of leukemia mice. Proteomics 7: 3305-3317, 2007.

50. Kaji H, Tsuji T, Mawuenyega KG, Wakamiya A, Taoka M and Isobe T: Profiling of Caenorhabditis elegans proteins using two-dimensional gel electrophoresis and matrix assisted laser desorption/ionization-time of flight-mass spectrometry. Electrophoresis 21: 1755-1765, 2000.

51. Lam YW, Evans VC, Heesom KJ, Lamond AI and Matthews DA: Proteomics analysis of the nucleolus in adenovirus-infected cells. Mol Cell Proteomics 9: 117-130, 2010.

52. Kuo CT, Hsu MJ, Chen BC, et al: Denbinobin induces apoptosis in human lung adenocarcinoma cells via Akt inactivation, Bad activation, and mitochondrial dysfunction. Toxicol Lett 177: 48-58, 2008.

53. Lahiry L, Saha B, Chakraborty J, et al: Theaflavins target Fas/caspase- 8 and $\mathrm{Akt} / \mathrm{pBad}$ pathways to induce apoptosis in p53-mutated human breast cancer cells. Carcinogenesis 31: 259-268, 2010

54. Hsu S, Lewis J, Singh B, et al: Green tea polyphenol targets the mitochondria in tumor cells inducing caspase 3-dependent apoptosis. Anticancer Res 23: 1533-1539, 2003.

55. Suganuma M, Kurusu M, Suzuki K, Tasaki E and Fujiki H: Green tea polyphenol stimulates cancer preventive effects of celecoxib in human lung cancer cells by upregulation of GADD153 gene. Int J Cancer 119: 33-40, 2006.

56. Datta SR, Dudek H, Tao X, et al: Akt phosphorylation of BAD couples survival signals to the cell-intrinsic death machinery. Cell 91: 231-241, 1997

57. Zha J, Harada H, Yang E, Jockel J and Korsmeyer SJ: Serine phosphorylation of death agonist BAD in response to survival factor results in binding to 14-3-3 not BCL-X(L). Cell 87: 619-628, 1996.

58. Huang CH, Tsai SJ, Wang YJ, Pan MH, Kao JY and Way TD: EGCG inhibits protein synthesis, lipogenesis, and cell cycle progression through activation of AMPK in p53 positive and negative human hepatoma cells. Mol Nutr Food Res 53: 1156-1165, 2009.

59. Davenport A, Frezza M, Shen M, et al: Celastrol and an EGCG pro-drug exhibit potent chemosensitizing activity in human leukemia cells. Int J Mol Med 25: 465-470, 2010.

60. Wang YC and Bachrach U: The specific anti-cancer activity of green tea (-)-epigallocatechin-3-gallate (EGCG). Amino Acids 22: $131-143,2002$

61. Khan N and Mukhtar H: Multitargeted therapy of cancer by green tea polyphenols. Cancer Lett 269: 269-280, 2008.

62. Konishi H, Tanaka M, Takemura Y, et al: Activation of protein kinase $\mathrm{C}$ by tyrosine phosphorylation in response to $\mathrm{H}_{2} \mathrm{O}_{2}$. Proc Natl Acad Sci USA 94: 11233-11237, 1997.

63. Natsume $\mathrm{H}$, Adachi $\mathrm{S}$, Takai $\mathrm{S}$, et al: (-)-Epigallocatechin gallate attenuates the induction of HSP27 stimulated by sphingosine 1-phosphate via suppression of phosphatidylinositol 3-kinase/ Akt pathway in osteoblasts. Int J Mol Med 24: 197-203, 2009.

64. El Golli Bennour E, Rodriguez-Enfedaque A, Bouaziz C, Ladjimi M, Renaud F and Bacha $\mathrm{H}$ : Toxicities induced in cultured human hepatocarcinoma cells exposed to ochratoxin A: oxidative stress and apoptosis status. J Biochem Mol Toxicol 23: 87-96, 2009. 